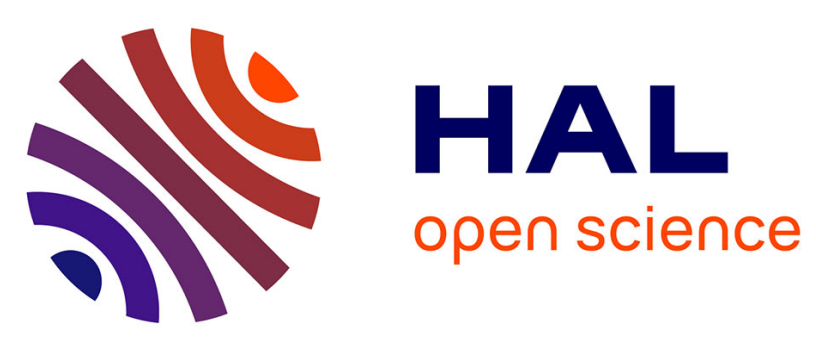

\title{
The effect of internal rotation in p-methyl anisole studied by microwave spectroscopy
}

Lynn Ferres, Wolfgang Stahl, Isabelle Kleiner, Ha Vinh Lam Nguyen

\section{To cite this version:}

Lynn Ferres, Wolfgang Stahl, Isabelle Kleiner, Ha Vinh Lam Nguyen. The effect of internal rotation in p-methyl anisole studied by microwave spectroscopy. Journal of Molecular Spectroscopy, 2018, 343, pp.44-49. 10.1016/j.jms.2017.09.008 . hal-03183097

\section{HAL Id: hal-03183097 https://hal.science/hal-03183097}

Submitted on 26 Mar 2021

HAL is a multi-disciplinary open access archive for the deposit and dissemination of scientific research documents, whether they are published or not. The documents may come from teaching and research institutions in France or abroad, or from public or private research centers.
L'archive ouverte pluridisciplinaire HAL, est destinée au dépôt et à la diffusion de documents scientifiques de niveau recherche, publiés ou non, émanant des établissements d'enseignement et de recherche français ou étrangers, des laboratoires publics ou privés. 


\section{The Effect of Internal Rotation in p-Methyl Anisole Studied by Microwave Spectroscopy}

Lynn Ferres $^{\mathrm{a}}$, Wolfgang Stahl ${ }^{\mathrm{a}}$, Isabelle Kleiner ${ }^{\mathrm{b}}$, Ha Vinh Lam Nguyen ${ }^{\mathrm{b}}$

a Institute of Physical Chemistry, RWTH Aachen University, Landoltweg 2, D-52074 Aachen, Germany; b Laboratoire Interuniversitaire des Systèmes Atmosphériques (LISA), CNRS UMR 7583, Université Paris-Est Créteil, Université Paris Diderot, 61 avenue du Général de Gaulle, F-94010 Créteil cedex, France

* Corresponding author: lam.nguyen@lisa.u-pec.fr

Keywords: structure determination, phenyl ring, rotational spectroscopy, microwave spectroscopy, large amplitude motion, internal rotation

\section{Abstract}

The Fourier transform microwave spectrum of $p$-methyl anisole, $\mathrm{CH}_{3} \mathrm{C}_{6} \mathrm{H}_{4} \mathrm{OCH}_{3}$, was measured in the frequency range from 2 to $26.5 \mathrm{GHz}$ under molecular jet conditions. The conformer analysis yielded only one stable conformer, in which all heavy atoms are co-planar, and which was identified after analyzing the spectrum by comparison with the results from quantum chemical calculations. The barrier of the $V_{3}$ potential of the ring methyl rotor was found to be $49.374548(1) \mathrm{cm}^{-1}$, and was compared with that found in other para-substituted toluenes as well as in o-methyl anisole. A comparison between two theoretical approaches treating internal rotations, the rho axis method (program $B E L G I-C_{s}$ ) and combined axis method (program XIAM), is also performed.

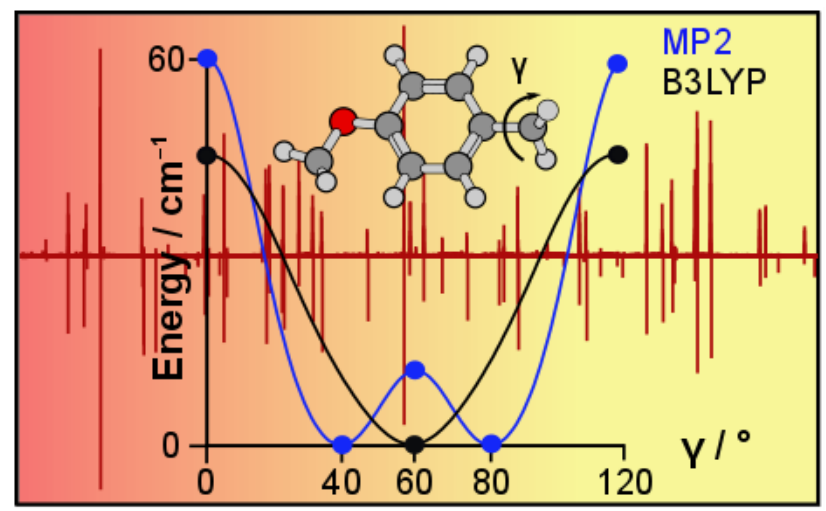




\section{Introduction}

p-Methyl anisole (PMA, also known as 4-methyl anisole, 4-methoxy toluene, or 1-methoxy-4methyl benzene) is a colorless liquid with an almond-similar smell and a vapor pressure of 2 $\mathrm{hPa}\left(20^{\circ} \mathrm{C}\right)$.

PMA is a molecule of spectroscopic interest due to its large amplitude motions (LAM). Methyl anisole exists as three structural isomers with the ring methyl group in ortho, meta, and para position relative to the methoxy group. Although some chemical properties such as vapor pressure, color, smell, and acidity are similar, the effect of methyl internal rotation which often depends on the steric and electronic surroundings can be completely different for these isomers. This has been frequently observed in previous investigations on aromatic ring containing molecules by rotational spectroscopy. For example, the barrier to internal rotation of the acetyl methyl group differs by about $100 \mathrm{~cm}^{-1}$ in two conformers (cis and trans) of 2acetyl-5-methylfuran [1]. In $o$-cresol, Welzel et al. reported barriers of the $V_{3}$ potentials of 371.05(41) and 669.10(51) $\mathrm{cm}^{-1}$ for the anti and syn conformers, respectively [2]. Quite different barrier heights were also found for three isomers of dimethylbenzaldehyde [3].

Our recent studies on the microwave spectrum of $o$-methyl anisole [4] have shown that the ring methyl group undergoes internal rotation with a barrier of the $V_{3}$ potential of approximately $444 \mathrm{~cm}^{-1}$, whereas the effect arising from the methoxy methyl group could not be resolved. Several investigations in the literature pointed out, that the barrier of the $V_{3}$ potential is drastically lower if the ring methyl group moves from the ortho to the paraposition. Back to the case of $o$-cresol, intermediate barrier heights with dominating $V_{3}$ potentials and negligible $V_{6}$ components were found [2]. Compared to the very low $V_{3}$ term of $18.39(3) \mathrm{cm}^{-1}$ and a significant $V_{6}$ contribution of $-7.3(6) \mathrm{cm}^{-1}$ found in $p$-cresol [5], the $V_{3}$ value decreases by one order of magnitude. Therefore, the aim of the present work on PMA is an accurate determination of its structure as well as the barrier to internal rotation of the ring 
methyl group and subsequently a comparison with the torsional barriers of $o$-methyl anisole and other toluene derivatives possessing methyl group in para position.

\section{Quantum Chemical Calculations}

For the structure determination, a combination of microwave spectroscopy and quantum chemistry has lately developed into a powerful and reliable tool. With 9 heavy atoms and 10 protons, PMA is yet a relatively small aromatic substance, at the same time being a mediumsized molecule in the realm of precise spectroscopic studies. Determining its structure by the atom-by-atom substitution method, is already becoming a tedious task for the heavy atom backbone while - in natural abundance - the positions of the hydrogen atoms cannot be determined at all. Combining the experimentally deduced molecular parameters with quantum chemical results, a detailed and precise statement on the three-dimensional structure of PMA becomes possible. This combination was applied successfully in many of our previous studies, e.g. in Ref. [6-8].

All quantum chemical calculations were carried out using the program package GAUSSIAN09 [9]. Because calculations for some other molecules containing aromatic rings like phenetole [10], $o$-methyl anisole [4], and 2,5-dimethylthiophene [11] have shown that the MP2/6-311++G(d,p) level of theory, which we frequently used for geometry optimizations, yielded geometry parameters in reasonable agreement with the experimental values, we also use this level in all calculations for PMA if not stated otherwise.

All conformations of PMA can be created by rotating the methoxy group about the $\mathrm{O}_{11}-\mathrm{C}_{5}$ bond (for atom numbering see Fig. 1). We calculated a potential energy curve by varying the dihedral angle $\alpha=\angle\left(\mathrm{C}_{12}, \mathrm{O}_{11}, \mathrm{C}_{5}, \mathrm{C}_{4}\right)$ in $10^{\circ}$ steps while all other geometry parameters were optimized. Because of the (heavy atom) linearity of the methoxy and the (heavy atom) planarity of the tolyl moieties, the calculations for $\alpha$ values from $0^{\circ}$ to $180^{\circ}$ was 
sufficient. The calculated energies were parameterized using a Fourier expansion based on terms with the correct symmetry of $\alpha$ with the corresponding coefficients given in Table S-1 in the supplementary material. Using these Fourier coefficients, the potential energy curve was drawn as illustrated in Fig. 2, showing that PMA has two stable $\mathrm{C}_{\mathrm{s}}$ conformers at $\alpha=0^{\circ}$ $\left(\mathrm{I}_{\mathrm{a}}\right)$ and $180^{\circ}\left(\mathrm{I}_{\mathrm{b}}\right)$ which are equivalent and can be transformed into each other by a rotation of $180^{\circ}$ of the tolyl group with a torsional barrier of about $634 \mathrm{~cm}^{-1}$.

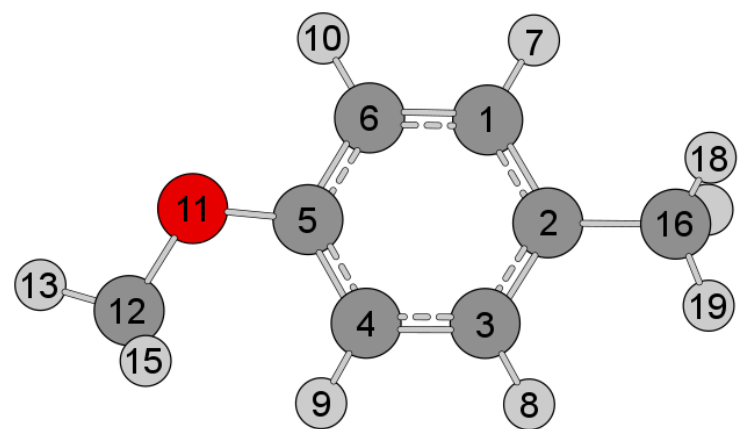

Fig. 1. Molecular structure of the only conformer of $p$-methyl anisole optimized at the MP2/6$311++\mathrm{G}(\mathrm{d}, \mathrm{p})$ level of theory. The proton $\mathrm{H}_{14}$ is located behind $\mathrm{H}_{15}$.

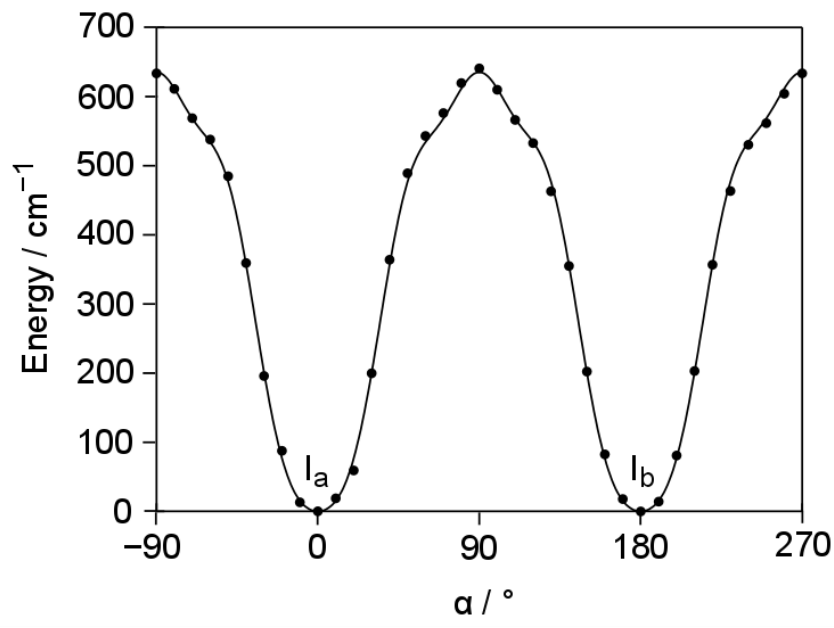

Fig. 2. The potential energy curve of $p$-methyl anisole obtained by rotating the methoxy group about the $\mathrm{O}_{11}-\mathrm{C}_{5}$ bond (for atom numbering, see Fig. 1) by varying the dihedral angle $\alpha=\angle\left(\mathrm{C}_{12}, \mathrm{O}_{11}, \mathrm{C}_{5}, \mathrm{C}_{4}\right)$ in a grid of $10^{\circ}$ at the MP2/6-311++G(d,p) level of theory. The relative energies with respect to the lowest energy conformation with $E=-385.0433328$ Hartree are given. The two stable $\mathrm{C}_{\mathrm{s}}$ conformers at $\alpha=0^{\circ}\left(\mathrm{I}_{\mathrm{a}}\right)$ and $180^{\circ}\left(\mathrm{I}_{\mathrm{b}}\right)$ are equivalent and can be transformed into each other by a rotation of $180^{\circ}$ of the tolyl group with a torsional barrier of about $634 \mathrm{~cm}^{-1}\left(7.58 \mathrm{~kJ} \cdot \mathrm{mol}^{-1}\right)$. 
The fully optimized geometry for the minimum $I_{a}$ was calculated afterwards and depicted in Fig. 1. The Cartesian coordinates are given in Table S-2 in the Supporting Information. The predicted rotational constants are $A=4.756 \mathrm{GHz}, B=0.983 \mathrm{GHz}$, and $C=$ $0.823 \mathrm{GHz}$ and the dipole moment components $\mu_{a}=-0.09 \mathrm{D}, \mu_{b}=-1.38 \mathrm{D}$, and $\mu_{c}=-0.01 \mathrm{D}$. The signs are given with respect to the coordinates given in Table S-2. Therefore, we expected intense $b$-type, very weak $a$-type, and no $c$-type transitions in the microwave spectrum. Ray's asymmetry parameter $[12] \kappa=-0.91$ indicates that PMA is a near prolate top. Frequency calculations confirmed that the structure given in Fig. 1 is a true minimum and not saddle point. This is surprising because the MP2/6-311++G(d,p) level of theory often yields one imaginary vibrational mode for this kind of molecules, which is a bending vibration of the phenyl ring $[4,11,13]$.

While the structure of PMA is relatively simple because of the planarity of the phenyl ring, the LAM of this molecule is much more challenging with two inequivalent methyl internal rotations. The barrier heights of the methoxy methyl and the ring methyl group were calculated by varying the dihedral angles $\beta=\angle\left(\mathrm{H}_{13}, \mathrm{C}_{12}, \mathrm{O}_{11}, \mathrm{C}_{5}\right)$ and $\gamma=\angle\left(\mathrm{C}_{1}, \mathrm{C}_{2}, \mathrm{C}_{16}, \mathrm{H}_{19}\right)$, respectively, in a grid of $10^{\circ}$. A rotation of $120^{\circ}$ was sufficient due to the three-fold symmetry of the methyl groups. For the methoxy methyl group, we found a barrier of the $V_{3}$ potential of $1034.5 \mathrm{~cm}^{-1}$; however, the potential form is remarkably asymmetric, as shown in Fig. 3. The barrier of the $V_{3}$ potential for the ring methyl group is $58.8 \mathrm{~cm}^{-1}$ with significant $V_{6}$ contributions (given in Fig. 4), as can be also recognized from the Fourier coefficients listed in Table S-3 in the supplementary material. In Fig. 4, the blue curve (calculated at the MP2/6$311++\mathrm{G}(\mathrm{d}, \mathrm{p})$ level of theory) shows that double minimum potentials exist between the region of $\gamma=0^{\circ}-120^{\circ}$ as well as $120^{\circ}-240^{\circ}$ and $240^{\circ}-360^{\circ}$ with local maxima at $\gamma_{\max }=60^{\circ}$, $180^{\circ}$, and $300^{\circ}$. These local maxima correspond to the conformation I depicted in Fig. 5. The 
minima of the blue curve in Fig. 4 at $\gamma_{\min } \approx \gamma_{\max } \pm 21^{\circ}$ correspond to the conformations II and II* in Fig. 5.

We repeated the optimizations using density functional theory at the B3LYP/6$311++\mathrm{G}(\mathrm{d}, \mathrm{p})$ level of theory. Here, we found in contrary to the results obtained at the MP2/6$311++\mathrm{G}(\mathrm{d}, \mathrm{p})$ level a $V_{3}$ potential without significant $V_{6}$ contributions (see also the Fourier coefficients given in Table S-3). In the potential curve in black in Fig. 4, simple global energy minima exist at $\gamma_{\max }$, whereas the minima at $\gamma_{\max } \pm 21^{\circ}$ do not occur.

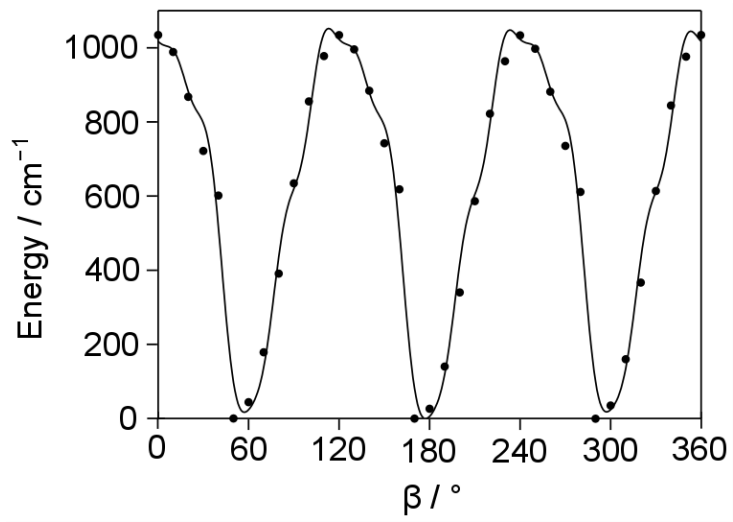

Fig. 3. The potential energy curve obtained by rotating the methoxy methyl group about the $\mathrm{C}_{12}-\mathrm{O}_{11}$ bond. The dihedral angle $\beta=\angle\left(\mathrm{H}_{13}, \mathrm{C}_{12}, \mathrm{O}_{11}, \mathrm{C}_{5}\right)$ was varied in a grid of $10^{\circ}$, while all other molecular parameters were optimized at the MP2/6-311++G(d,p) level. Relative energies with respect to the lowest energy conformations with the absolute energies $E=-385.0433319$ Hartree are used. The barrier of the $V_{3}$ potential is $1034.5 \mathrm{~cm}^{-1}\left(12.38 \mathrm{~kJ} \cdot \mathrm{mol}^{-1}\right)$. 


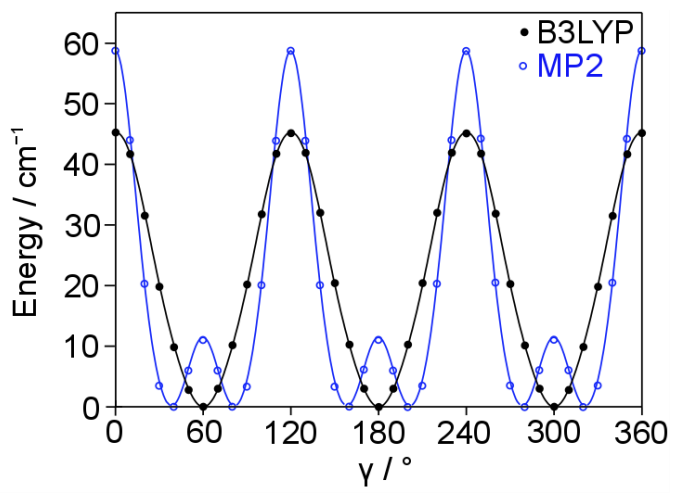

Fig. 4. The potential energy curve obtained by rotating the ring methyl group about the $\mathrm{C}_{2}-\mathrm{C}_{16}$ bond. The dihedral angle $\gamma=\angle\left(\mathrm{C}_{1}, \mathrm{C}_{2}, \mathrm{C}_{16}, \mathrm{H}_{19}\right)$ was varied in a grid of $10^{\circ}$ at starting values of $-1.2^{\circ}$ and $180.6^{\circ}$ for $\alpha$ and $\beta$, respectively (values obtained from the geometry given in Fig. 1), while all other molecular parameters including $\alpha$ and $\beta$ were optimized at the MP2/6-311++G(d,p) and B3LYP/6$311++\mathrm{G}(\mathrm{d}, \mathrm{p})$ levels. Relative energies with respect to the lowest energy conformations with the absolute energies $\mathrm{E}=-385.0433328$ and -386.1944856 Hartree, respectively, are used.

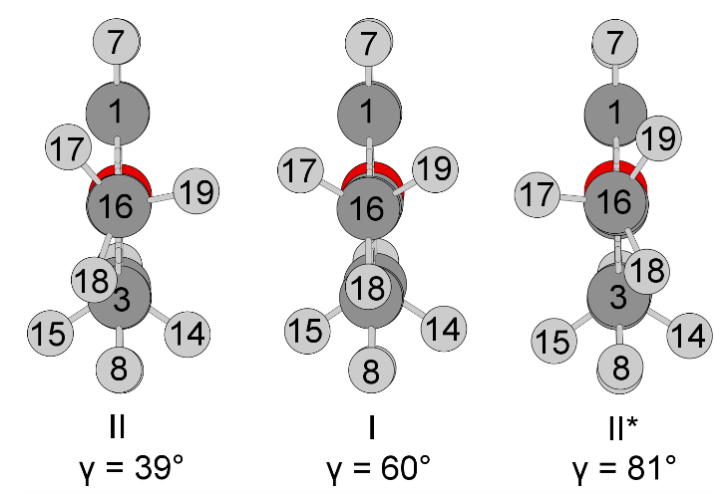

Fig. 5. View along the $\mathrm{C}_{2}-\mathrm{C}_{16}$ axis, showing three conformations of $p$-methyl anisole with different positions of the ring methyl group. Conformation I corresponds to the local maxima $\gamma_{\max }$ between the regions of $\gamma=0^{\circ}-120^{\circ}$ as well as $120^{\circ}-240^{\circ}$ and $240^{\circ}-360^{\circ}$ in Fig. 4 calculated at the MP2/6$311++\mathrm{G}(\mathrm{d}, \mathrm{p})$ level, which are the global minima calculated at the B3LYP/6-311++G(d,p) level. Conformation II and II* correspond to the local minima at $\gamma_{\min } \approx \gamma_{\max } \pm 21^{\circ}$ in Fig. 4 calculated at the MP2/6-311++G(d,p) level, which do not occur in calculations at the B3LYP/6-311++G(d,p) level. 


\section{Microwave spectroscopy}

\subsection{Experimental Section}

The molecular jet Fourier transform microwave spectrometer used for this study is a modified versions of that described in Ref. [14], which operates in the frequency range from 2.0 to 26.5 GHz. The spectrometers can be used in two different modes, the single frequency mode and the broadband scan mode. The single frequency mode allows to observe a spectral range of only about $1 \mathrm{MHz}$ limited by the width of the resonator modes. In the scan mode a wide frequency range can be automatically scanned by a series of single frequency experiments.

PMA with a purity of $98 \%$ was purchased from TCI, Eschborn, Germany, and used without further purification. The compound was soaked on a pipe cleaner and inserted in a stainless steel tube in front of the nozzle. Under helium stream at a backing pressure of $200 \mathrm{kPa}$, the PMA-He mixture was expanded through a pulsed nozzle into a vacuum chamber to generate the molecular jet. Helium was used as carrier gas since the rotational temperature is higher than in neon or argon. This enabled us to observe a wider range of $J$ and $K$ states, which is important for the determination of some centrifugal distortion and internal rotation parameters.

The measurements were carried out first in the rapid-scan mode, where overlapping spectral segments from 10 to $14 \mathrm{GHz}$ were recorded with a step size of $0.25 \mathrm{MHz}$. The broadband scan is given in the upper trace of Fig. 6. In the single frequency mode all lines are split into doublets due to the Doppler effect. The average value of the line widths was $25 \mathrm{kHz}$, the line positions could be determined with an accuracy of about $2.5 \mathrm{kHz}$. 


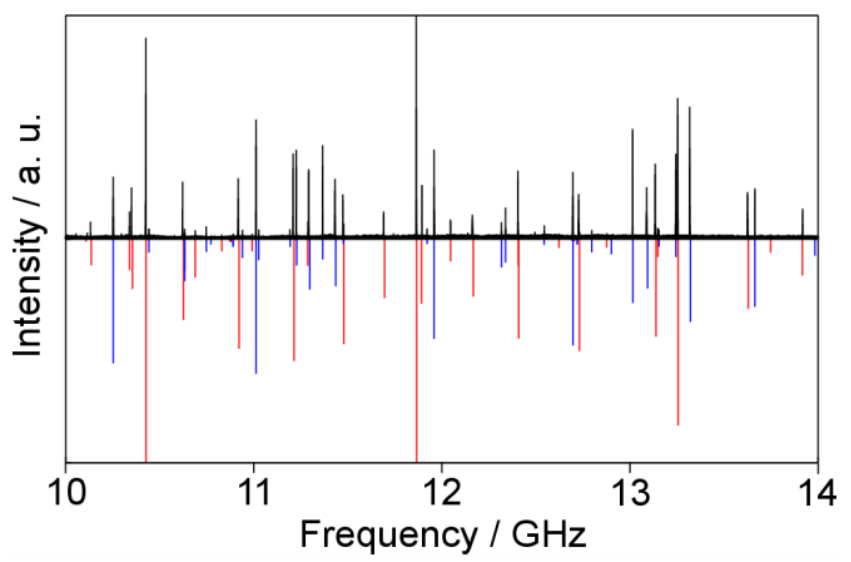

Fig. 6. A broadband scan of p-methyl anisole from 10 to $14 \mathrm{GHz}$. The experimental spectrum is the upper trace. The lower trace indicates the theoretical spectrum (A species in red and E species in blue) predicted using the molecular parameters deduced from a one-top fit using the program XIAM.

\subsection{Spectral assignment}

The barrier of the $V_{3}$ potential of the ring methyl group was calculated to be $58.8 \mathrm{~cm}^{-1}$, while the barrier height of the methoxy methyl group is $1034.5 \mathrm{~cm}^{-1}$ (see Section 2). Simple two-top predictions using the program XIAM [15] indicate that torsional splittings arising from the methoxy methyl group are smaller than $2 \mathrm{kHz}$, whereas those from the ring methyl group are much larger, up to $11.3 \mathrm{GHz}$ (torsional splitting of the $4_{23} \leftarrow 3_{12}$ transition). Therefore, we expect the spectrum of PMA to be that of a one-top molecule with resolvable splittings of only the ring methyl group into the torsional A and E species [16].

As a first step, we neglected the methyl internal rotation and treated PMA as an effective rigid-rotor, i.e. we only considered the A species. Because only the dipole moment component in $b$-direction is sufficiently large, we began with searching for $b$-type transitions. Using the calculated rotational constants given in Section 2, a theoretical spectrum between 10 and $14 \mathrm{GHz}$ was predicted using the program XIAM and compared to the experimental broadband scan mentioned in Section 3.1. The characteristic butterfly pattern of the $R$ branch $K_{\mathrm{a}}=2 \leftarrow 1$ could be recognized readily in the spectrum, leading to their straightforward 
assignment which fixed all the rotational constants. This enabled us to predict the whole rigidrotor spectrum with sufficient accuracy to find all remaining A species lines in the frequency range from $2-26.5 \mathrm{GHz}$. Surprisingly, we were able to measure some $a$-type transitions. Those lines are more intense than expected with the calculated dipole moment component $\mu_{a}$ $=0.07 \mathrm{D}$ (see Section 2). At this stage, 164 lines were fitted with the three rotational constants $A, B, C$ and five quartic centrifugal distortion constants to a root-mean-square (rms) deviation of $2.4 \mathrm{kHz}$, which is within the measurement accuracy.

As a next step, we took into account the methyl internal rotation and predicted both, the $\mathrm{A}$ and $\mathrm{E}$ species transitions. The initial barrier of the $V_{3}$ potential and the angle between the internal rotor axis and the principal $a$-axis was taken from $a b$ initio results in Section 2 . The rotational constant of the methyl group $F_{0}$ was fixed to the value of $160.16 \mathrm{GHz}$ calculated by ab initio. By comparing the theoretical and experimental broadband scan, the assignment was straightforward for some $b$-type lines with low $K_{\mathrm{a}}$ values and small A-E splittings. Other transitions with larger splittings were also assigned successfully by trial and error.

\subsection{Fits}

The program XIAM was used to fit 164 A species and 183 E species lines in the microwave spectrum of PMA to an rms deviation of $82.2 \mathrm{kHz}$, which is much larger than the measurement accuracy $(2.5 \mathrm{kHz})$. The molecular parameters are summarized as Fit A/E in Table 1. A list including all fitted transitions is given in Table S-4 in the supplementary material.

From our previous investigations on molecules of different chemical classes undergoing internal rotation with low barrier height such as 3-pentin-1-ol [17], allyl acetate [18], and Nethylacetamide [19], we know that E species transitions are often not well fitted with XIAM, 
because no higher order coupling terms between the internal rotation and the overall rotation can be easily implemented in this program to improve the quality of the fit.

As an alternative, a fit with the program $B E L G I-C_{s}[20]$ was carried out. A comparison of the two programs was described elsewhere and will not be repeated here [21,22]. The same data set was fitted to measurement accuracy with rms deviations of $2.1 \mathrm{kHz}$. Parameters, which can be transformed into the principal axis system by a rotation about the $c$-axis, are given as Fit BELGI in Table 1; all BELGI-Cs parameters in the rho axis system in Table 2. All fitted transitions along with their residuals are also listed in Table S-4 in the supplementary material.

\section{Discussion}

Fit A/E from the program XIAM in Table 1 can be improved by fixing the internal rotational parameters to the values obtained from the global fit and fitting only A species transitions. This fit is given as Fit A in Table 1. The standard deviation is then significantly reduced to 2.4 $\mathrm{kHz}$, which shows that the program XIAM can fit A species transitions of PMA perfectly, but not the E species.

The program BELGI-Cs can fit the same data set using 17 parameters to a rms deviation of $2.1 \mathrm{kHz}$. The rotational constants $A, B, C$, centrifugal distortion constants, the barrier of the $V_{3}$ potential, the reduced rotational constant of the internal rotor $F$, and the $D_{a b}$ parameter, which multiplies the $\mathbf{P}_{\mathrm{a}} \mathbf{P}_{\mathrm{b}}+\mathbf{P}_{\mathrm{b}} \mathbf{P}_{\mathrm{a}}$ operator and is due to the use of the rho axis system, were floated. Finally, some higher-order terms between the internal rotation and the global overall rotation $\left(F_{\mathrm{v}}, k_{1}, c_{1}\right.$, and $\left.D_{a b J}\right)$ were required to obtain a rms deviation very close to measurement accuracy. The $B E L G I-C_{s}$ fit also provides better predictive power than the $X I A M$ fit. However, for assignment purposes the program XIAM is more convenient to use.

The barrier of the $V_{3}$ potential of the ring methyl group is $49.374548(1) \mathrm{cm}^{-1}$ according to the XIAM fit. The values obtained by BELGI- $C_{s}$ agree within $1.3 \%$. The reduced 
barriers $s=4 V_{3} / 9 F$ as well as the methyl rotor angles in the BELGI- $C_{s}$ and the XIAM fits are also very similar (see Table 1). It should be noted that with the program XIAM, a strong correlation between $V_{3}$ and $I_{\gamma}$ is present, because only transitions in the ground torsional state are included in the analysis. Therefore, we fixed $I_{\gamma}$ to the calculated value corresponding to $F_{0}$ $=160.16 \mathrm{GHz}$ (see Section 3.2). In the case of $B E L G I-C_{s}$, the reduced rotational constant of the internal rotor $F$ could be fitted. We note that $F=F_{0} / r$ with $r=1-I_{\gamma} \sum_{g} \lambda_{g}^{2} / I_{g}$. The $I_{g}$ are the principal moments of inertia and the $\lambda_{g}$ the direction cosines between the principal axes of inertia $g \in\{a, b, c\}$ and the internal rotor axis. The six-fold contribution to the barrier is assumed to be negligible. However, with only ground state torsional transitions, it is impossible to test the validity of this assumption, as $V_{6}$ cannot be determined. On the other hand, we found that, contrary to the situation found for $p$-cresol [5], as well as calculations at the MP2/6-311++G(d,p) level of theory, the BELGI- $C_{s}$ fit is quite good if only the $V_{3}$ term is fitted. Therefore, we could determine the barrier of PMA without any ambiguities.

As mentioned in Section 2, calculations of the potential barrier of the ring methyl group at the MP2/6-311++G(d,p) level indicate double minimum potentials arising from a significant $V_{6}$ contribution, while the B3LYP/6-311++G(d,p) level predicts a normal threefold potential. This kind of inconsistency between the MP2 and B3LYP methods in combination with the $6-311++\mathrm{G}(\mathrm{d}, \mathrm{p})$ basis set has been quite often observed in previous studies such as diethyl ketone [23] and ethyl methyl ketone [24]. The calculations were repeated at various combinations of the MP2 and B3LYP methods with different basis set to check for convergence. The results are summarized in Table 3. None of the calculations using the B3LYP method shows double minimum potentials. In combination with the aug-cc-pVDZ and aug-cc-pVTZ, the barrier of the $V_{3}$ potential is calculated relatively well with deviation of about $3.5 \mathrm{~cm}^{-1}$ to the experimental value. In the contrary, all calculations using the MP2 method yield double minimum potentials. This effect did not occur in $o$-methyl anisole [4], 
where all levels of theory predicted three-fold potential for the internal rotation of the ring methyl group.

The $V_{6}$ contribution in the potential would generate additional splittings of the A and $\mathrm{E}$ torsional species of the three-fold rotor if the lowest torsional level $\left(18.85 \mathrm{~cm}^{-1}\right.$ in the case of PMA, value calculated by the program $B E L G I-C_{S}$ ) lies below the local maxima, as observed for pinacolone [25]. Because no additional splittings were observed experimentally, it is most likely not the case. This is further supported by sample calculations of the torsional energy levels based on the calculated potential parameters. Therefore, the absence of additional splittings cannot give any statement on the accuracy of the MP2 or B3LYP method.

Moreover, the barrier of the $V_{3}$ potential of $49.374548(1) \mathrm{cm}^{-1}$ obtained for PMA is an order of magnitude lower than that found in $o$-methyl anisole $\left(444.05(41) \mathrm{cm}^{-1}\right)$ [4]. A similar situation was observed for the anti and syn conformers of $o$-cresol with barriers of the $V_{3}$ potentials of $371.05(41)$ and $669.10(51) \mathrm{cm}^{-1}$, respectively [2], vs. the much lower $V_{3}$ term of $18.39(3) \mathrm{cm}^{-1}$ and a significant $V_{6}$ contribution of $-7.3(6) \mathrm{cm}^{-1}$ found in $p$-cresol [5]. In $p$ tolualdehyde, very low barrier of the $V_{3}$ potential of about $28.37 \mathrm{~cm}^{-1}$ with $V_{6}$ contribution of about $-5.33 \mathrm{~cm}^{-1}$ was found [26]. We believe that there is an intuitive explanation for the low barrier of the ring methyl group in para-substituted toluenes. If we consider toluene or a molecule with symmetric substituent at the para position like $p$-fluorotoluene, the frame has a perfect $\mathrm{C}_{2 \mathrm{v}}$ symmetry. In combination with the local $\mathrm{C}_{3 \mathrm{v}}$ symmetry of the ring methyl group, the $V_{3}$ contribution of the potential would be zero, and only a small $V_{6}$ term exists, which is $4.9 \mathrm{~cm}^{-1}$ in the case of toluene [27] and $4.8298(63) \mathrm{cm}^{-1}$ for $p$-fluorotoluene [28]. If the substituent is slightly asymmetric, such as an alcohol group in $p$-cresol, an aldehyde group in p-tolualdehyde, or a methoxy methyl group in PMA, the $\mathrm{C}_{2 \mathrm{v}}$ symmetry of the frame is slightly broken, causing a $V_{3}$ potential term. The smaller the substituent is $\left(\mathrm{OH}<\mathrm{CHO}<\mathrm{OCH}_{3}\right)$, the less the $\mathrm{C}_{2 \mathrm{v}}$ symmetry of the frame is broken, and consequently the lower the barrier of the $V_{3}$ 
potential becomes $\left(18.39(3) \mathrm{cm}^{-1}<28.37 \mathrm{~cm}^{-1}<49.374548(1) \mathrm{cm}^{-1}\right.$, respectively). In orthosubstituted toluene the frame has no longer $\mathrm{C}_{2 \mathrm{v}}$ symmetry. The $V_{3}$ potential term is therefore dominant; the $V_{6}$ potential becomes negligible.

Alvarez-Valtierra et al. have already reported on the LAM of PMA using fluorescence spectroscopy [29] with a barrier of the $V_{3}$ potential of $48.9(2) \mathrm{cm}^{-1}$ for the internal rotation of the ring methyl group. In the case of $o$-methyl anisole, the barrier height obtained from fluorescence spectroscopy differs by $99 \mathrm{~cm}^{-1}$ from that determined by microwave spectroscopy [4]. For PMA, the value of this parameter is much more consistent, and only a small difference of less than $1 \mathrm{~cm}^{-1}$ was found. On the other hand, the barrier height given by microwave spectroscopy is determined with much higher accuracy and is more reliable, since this parameter was only indirectly determined in fluorescence spectroscopy.

The rotational constants obtained from the XIAM and BELGI-C $C_{s}$ fits are similar; however, they do not agree within the errors, because different parameter sets were fitted (see Table 1 and 2) and the correlations among these parameters are different. The values calculated at the MP2/6-31G(d,p) level of theory (see Table 3) match the experimental values best. However, since the calculated constants refer to the equilibrium structure, whereas the experimental constants are effective constants, the accurately calculated values at the MP2/6$31 \mathrm{G}(\mathrm{d}, \mathrm{p})$ level are probably due to error compensations. This level of theory also yields quite good agreement between the calculated and the experimental results in the case of two very similar molecules, anisole and $o$-methyl anisole [4]. We note that at all levels of theory in use predict the $B$ and $C$ rotational constants quite well and overestimate the value of the $A$ rotational constant. 


\section{Acknowledgments}

We thank the Land Nordrhein-Westfalen for funds. Simulations were performed with computing resources granted by RWTH Aachen University. L.F. thanks the Faculté de Sciences et Technologie of the Université Paris-Est Créteil for travel funding, which enabled her to work at Paris for two months. Furthermore, we thank Viktoria Siebert for the contribution within her bachelor thesis.

\section{References}

[1] V. Van, W. Stahl, H. V. L. Nguyen, ChemPhysChem 17 (2016) 3223.

[2] A. Welzel, A. Hellweg, I. Merke, W. Stahl, J. Mol. Spectrosc. 215 (2002) 58.

[3] M. Tudorie, I. Kleiner, M. Jahn, J.-U. Grabow, M. Goubet, O. Pirali, J. Phys. Chem. A 117 (2013) 13636.

[4] L. Ferres, H. Mouhib, W. Stahl, H. V. L. Nguyen, ChemPhysChem. DOI 10.1002/cphc.201700276 (2017).

[5] A. Hellweg, C. Hättig, J. Chem. Phys. 127 (2007) 1.

[6] R. Kannengießer, W. Stahl, H. V. L. Nguyen, I. Kleiner, J. Phys. Chem. A 120 (2016) 3992.

[7] L. W. Sutikdja, W. Stahl, V. Sironneau, H. V. L. Nguyen, I. Kleiner, Chem. Phys. Lett. 663 (2016) 145.

[8] H.V.L. Nguyen, H. Mouhib, S. Klahm, W. Stahl, I. Kleiner, Phys. Chem. Chem. Phys. 15 (2013) 10012.

[9] M.J. Frisch, G.W. Trucks, H.B. Schlegel, G.E. Scuseria, M.A. Robb, J.R. Cheeseman, G. Scalmani, V. Barone, B. Mennucci, G.A. Petersson, H. Nakatsuji, M. Caricato, X. Li, H.P. Hratchian, A.F. Izmaylov, J. Bloino, G. Zheng, J.L. Sonnenberg, M. Hada, M. Ehara, K. Toyota, R. Fukuda, J. Hasegawa, M. Ishida, T. Nakajima, Y. Honda, O. Kitao, H. Nakai, T. Vreven, J.A. Montgomery, Jr., J.E. Peralta, F. Ogliaro, M. Bearpark, J.J. Heyd, E. Brothers, K.N. Kudin, V.N. Staroverov, R. Kobayashi, J. Normand, K. Raghavachari, A. Rendell, J.C. Burant, S.S. Iyengar, J. Tomasi, M. Cossi, N. Rega, J.M. Millam, M. Klene, J.E. Knox, J.B. Cross, V. Bakken, C. Adamo, J. Jaramillo, R. Gomperts, R.E. Stratmann, O. Yazyev, A.J. Austin, R. Cammi, C. Pomelli, J.W. Ochterski, R.L. Martin, K. Morokuma, V.G. Zakrzewski, G.A. Voth, P. Salvador, J.J. Dannenberg, S. Dapprich, A.D. Daniels, O. Farkas, J.B. Foresman, J.V. Ortiz, J. Cioslowski and D.J. Fox, Gaussian 09, Revision A.02, Gaussian, Inc., Wallingford CT, 2009.

[10] L. Ferres, W. Stahl, H. V. L. Nguyen, Mol. Phys. 114 (2016) 2788.

[11] V. Van, W. Stahl, H.V.L. Nguyen, Phys. Chem. Chem. Phys. 17 (2015) 32059. 
[12] D. S. Ray, Z. Physik 78 (1932) 74.

[13] D. Moran, A. C. Simmonett, F. E. Leach, W. D. Allen, P. v. R. Schleyer, H. F. Schaefer, J. Am. Chem. Soc. 128 (2006) 9342.

[14] J.-U. Grabow, W. Stahl, H. Dreizler, Rev. Sci. Instrum. 67 (1996) 4072.

[15] H. Hartwig and H. Dreizler, Z. Naturforsch. 51a (1996) 923.

[16] H. Dreizler, Z. Naturforsch. 16a (1961) 1354.

[17] K. Eibl, R. Kannengießer, W. Stahl, H. V. L. Nguyen, I. Kleiner, Mol. Phys. 114 (2016) 3483.

[18] H. V. L. Nguyen, H. Mouhib, W. Stahl, I. Kleiner, Mol. Phys. 108 (2010) 763.

[19] R. Kannengießer, M. J. Lach, W. Stahl, H. V. L. Nguyen, ChemPhysChem. 16 (2015) 1906.

[20] J.T. Hougen, I. Kleiner, M. Godefroid, J. Mol. Spectrosc. 163 (1994) 559.

[21] D. Jelisavac, D. C. Cortés-Gómez, H. V. L. Nguyen, L. W. Sutikdja, W. Stahl, I. Kleiner, J. Mol. Spectrosc. 257 (2009) 111.

[22] H. V. L. Nguyen, A. Jabri, V. Van, W. Stahl, J. Phys. Chem. A 118 (2014) 12130.

[23] H. V. L. Nguyen, W. Stahl, Chem. Phys. Chem. 12 (2011) 1900.

[24] H. V. L. Nguyen, V. Van, W. Stahl, I. Kleiner, J Chem. Phys. 140 (2014) 214303.

[25] Y. Zhao, H. V. L. Nguyen, W. Stahl, J. T. Hougen, J. Mol. Spectrosc. 318 (2015) 91.

[26] H. Saal, J.-U. Grabow, A. Hight-Walker, J. T. Hougen, W. Caminati, I. Kleiner, presentation \#WH07, 65th Ohio State University International Symposium on Molecular Spectroscopy, Columbus, Ohio, U.S.A., June 2010.

[27] H. D. Rudolph, H. Dreizler, A. Saeschke, P. Z. Wendling, Z. Naturforsch. 22a (1967) 940.

[28] J. Rottstegge, H. Hartwig, H. Dreizler, J. Mol. Struct. 478 (1999) 37.

[29] L. Alvarez-Valtierra, J. T. Yi and D. W. Pratt, Phys. Chem. Chem. Phys 12 (2010) 8323. 
Table 1. Molecular parameters of $p$-methyl anisole in the principal axis system obtained by the programs $X I A M$ and $B E L G I-C_{s}$.

\begin{tabular}{|c|c|c|c|c|c|}
\hline Par. $^{\mathrm{a}}$ & Unit & Fit $\mathbf{A} / \mathbf{E}$ & Fit $A^{b}$ & Fit BELGI & Calc. $^{c}$ \\
\hline$A$ & $\mathrm{MHz}$ & $4783.9078(68)$ & $4783.91962(21)$ & $4784.8097(19)$ & 4756.0299 \\
\hline$B$ & $\mathrm{MHz}$ & $983.7432(15)$ & $983.741406(37)$ & $983.64740(25)$ & 982.6510 \\
\hline C & $\mathrm{MHz}$ & $824.7913(14)$ & $824.789801(36)$ & $824.74834(18)$ & 822.8805 \\
\hline$\Delta_{J}$ & $\mathrm{kHz}$ & $0.0262(37)$ & $0.01996(16)$ & $0.02130(11)$ & 0.01961217 \\
\hline$\Delta_{J K}$ & $\mathrm{kHz}$ & $-0.083(33)$ & $-0.0307(11)$ & $-0.04565(92)^{\mathrm{d}}$ & -0.03237823 \\
\hline$\Delta_{K}$ & $\mathrm{kHz}$ & & $1.382(16)$ & $0.715(19)^{\mathrm{d}}$ & 0.89904515 \\
\hline$\delta_{J}$ & $\mathrm{kHz}$ & $0.0046(12)$ & $-0.004047(46)$ & $4.521(37)^{\mathrm{d}}$ & 0.00396224 \\
\hline$\delta_{K}$ & $\mathrm{kHz}$ & & $-0.000218(16)$ & $0.0625(26)^{\mathrm{d}}$ & 0.04729138 \\
\hline$V_{3}$ & $\mathrm{~cm}^{-1}$ & $49.6370(1)$ & 49.6370 & $48.7400(93)$ & 58.8 \\
\hline$D p i_{2 J}$ & $\mathrm{kHz}$ & $-5.30(36)$ & -5.30 & & \\
\hline$D p i_{2 K}$ & $\mathrm{MHz}$ & $0.3618(23)$ & 0.3618 & & \\
\hline $\mathrm{Dpi}_{2-}$ & $\mathrm{kHz}$ & $-4.69(13)$ & -4.69 & & \\
\hline$\angle(\mathrm{i}, a)$ & $\circ$ & $6.9597(2)$ & 6.9597 & $7.01600(32)$ & 6.96 \\
\hline$\angle(\mathrm{i}, b)$ & $\circ$ & $83.0403(2)$ & 83.0403 & $82.98400(32)$ & 83.10 \\
\hline$\angle(\mathrm{i}, c)$ & $\circ$ & $90.00^{\mathrm{e}}$ & 90.00 & $90.00^{\mathrm{e}}$ & 89.11 \\
\hline$s^{\mathrm{f}}$ & & 4.00752 & & 3.97574 & \\
\hline $\mathrm{N}_{\mathrm{A}} / \mathrm{N}_{\mathrm{E}^{\mathrm{g}}}^{\mathrm{g}}$ & I & 347 & 164 & 347 & \\
\hline $\mathrm{rms}^{\mathrm{h}}$ & $\mathrm{kHz}$ & 82.2 & 2.4 & 2.1 & \\
\hline
\end{tabular}

a All parameters refer to the principal axis system. Watson's A reduction and $I^{r}$ representation were used. ${ }^{b}$ Includes only A species transitions from the internal rotation of the ring methyl rotor, while the internal rotational parameters are fixed to the values obtained from the global Fit A/E. Number of lines. ${ }^{\mathrm{c}}$ Centrifugal distortion constants obtained from anharmonic frequency calculations at the B3LYP/6-311++G(d,p) level of theory, all other values from geometry optimizations at the MP2/6$311++\mathrm{G}(\mathrm{d}, \mathrm{p})$ level. Standard deviation of the fit. ${ }^{\mathrm{d}}$ Values in the rho axis system. ${ }^{\mathrm{e}}$ Fixed due to the planarity of all heavy atoms. ${ }^{\mathrm{f}}$ Reduced barrier, defined as $s=4 V_{3} / 9 \mathrm{~F} .{ }^{\mathrm{g}}$ Number of the A and E species lines $\left(\mathrm{N}_{\mathrm{A}} / \mathrm{N}_{\mathrm{E}}\right) .{ }^{\mathrm{h}}$ Root-mean-square deviation of the fit. 
Table 2. Spectroscopic constants of $p$-methyl anisole in the rho axis system obtained with the program $B E L G I-C_{s}$.

\begin{tabular}{lllr}
\hline Operator & Unit & Value $^{\mathrm{c}}$ \\
\hline $\mathbf{P}_{\mathrm{a}}{ }^{2}$ & $\mathrm{~A}$ & $\mathrm{GHz}$ & $4.7823783(19)$ \\
$\mathbf{P}_{\mathrm{b}}{ }^{2}$ & $\mathrm{~B}$ & $\mathrm{GHz}$ & $0.98607894(12)$ \\
$\mathbf{P}_{\mathrm{c}}{ }^{2}$ & $\mathrm{C}$ & $\mathrm{GHz}$ & $0.82474835(18)$ \\
$\frac{1}{2}(1-\cos 3 \gamma)$ & $V_{3}$ & $\mathrm{~cm}^{-1}$ & $48.7400(93)$ \\
$\mathbf{P}_{\mathrm{a}} \mathbf{P}_{\gamma}$ & $\rho$ & $\mathrm{unitless}$ & $0.0296818(14)$ \\
$-\mathbf{P}^{4}$ & $D_{J}$ & $\mathrm{kHz}$ & $0.02130(11)$ \\
$-\mathbf{P}^{2} \mathbf{P}_{\mathrm{a}}{ }^{2}$ & $D_{J K}$ & $\mathrm{kHz}$ & $-0.04565(92)$ \\
$-\mathbf{P}_{\mathrm{a}}{ }^{4}$ & $D_{K}$ & $\mathrm{kHz}$ & $0.715(19)$ \\
$-2 \mathbf{P}^{2}\left(\mathbf{P}_{\mathrm{b}}{ }^{2}-\mathbf{P}_{\mathrm{c}}{ }^{2}\right)$ & $\delta_{J}$ & $\mathrm{~Hz}$ & $4.521(37)$ \\
$-\left\{\mathbf{P}_{\mathrm{a}}{ }^{2},\left(\mathbf{P}_{\mathrm{b}}{ }^{2}-\mathbf{P}_{\mathrm{c}}{ }^{2}\right)\right\}$ & $\delta_{K}$ & $\mathrm{kHz}$ & $0.0625(26)$ \\
$\left\{\mathbf{P}_{\mathrm{a}}, \mathbf{P}_{\mathrm{b}}\right\}$ & $D_{a b}$ & $\mathrm{GHz}$ & $0.0961078(44)$ \\
$\left\{\mathbf{P}_{\mathrm{a}}, \mathbf{P}_{\mathrm{b}}\right\}(1-\cos 3 \gamma)$ & $d_{a b}$ & $\mathrm{MHz}$ & $-1.5508(91)$ \\
$\mathbf{P}^{2}\left\{\mathbf{P}_{\mathrm{a}}, \mathbf{P}_{\mathrm{b}}\right\}(1-\cos 3 \gamma)$ & $d_{a b J}$ & $\mathrm{kHz}$ & $-0.0346(13)$ \\
$\mathbf{P}_{\gamma}{ }^{2}$ & $F$ & $\mathrm{GHz}$ & $163.346(20)$ \\
$\mathbf{P}^{2}(1-\cos 3 \gamma)$ & $F_{v}$ & $\mathrm{MHz}$ & $0.06162(28)$ \\
$\mathbf{P}_{\mathrm{a}}{ }^{3} \mathbf{P}_{\gamma}$ & $k_{1}$ & $\mathrm{MHz}$ & $0.01074(76)$ \\
$2 \mathbf{P}_{\gamma}{ }^{2}\left(\mathbf{P}_{\mathrm{b}}{ }^{2}-\mathbf{P}_{\mathrm{c}}{ }^{2}\right)$ & $c_{1}$ & $\mathrm{kHz}$ & $-2.470(12)$ \\
& $\mathrm{N}_{\mathrm{A}} / \mathrm{N}_{\mathrm{E}}$ & $\mathrm{kHz}$ & $164 / 183$ \\
& $\mathrm{rms}$ & & $2.3 / 1.9$ \\
& & &
\end{tabular}

a All constants refer to the rho axis system. Therefore, the inertia tensor is not diagonal and the constants cannot be directly compared to those referring to the principal axis system. $\mathbf{P}_{\mathrm{a}}, \mathbf{P}_{\mathrm{b}}$, and $\mathbf{P}_{\mathrm{c}}$ are the components of the overall rotational angular momentum. $\mathbf{P}_{\gamma}$ is the angular momentum of the internal rotor rotating around the internal rotor axis by an angle $\gamma \cdot\{\mathrm{u}, \mathrm{v}\}$ is the anti-commutator $\mathrm{uv}+$ vu. ${ }^{\mathrm{b}}$ Parameters. The product of the parameter and operator from a given row yields the term actually used in the vibration-rotation-torsion Hamiltonian, except for $F, \rho$, and $A$, which occur in the Hamiltonian in the form $F\left(\mathbf{P}_{\gamma}-\rho \mathbf{P}_{\mathrm{a}}\right)^{2}+A \mathbf{P}_{\mathrm{a}}{ }^{\mathrm{c}}$ Values of the parameters from the present fit. Statistical uncertainties are shown as one standard uncertainty in unit of the last digit. 
Table 3. Rotational constants (in $\mathrm{GHz}$ ) and barrier of the $V_{3}$ potential of the ring methyl group (in $\mathrm{cm}^{-1}$ ) of $p$-methyl anisole calculated using the MP2 and B3LYP methods in combination with different basis sets and their deviations to the experimental values (obs. - calc.) in $\mathrm{MHz}$ and cm${ }^{-1}$, respectively.

\begin{tabular}{lllllllll}
\hline Basis set & $\boldsymbol{A}$ & $\boldsymbol{\Delta A}$ & $\boldsymbol{B}$ & $\boldsymbol{\Delta} \boldsymbol{B}$ & $\boldsymbol{C}$ & $\boldsymbol{\Delta}$ & $\boldsymbol{V}_{\mathbf{3}}$ & $\boldsymbol{\Delta} \boldsymbol{V}_{\mathbf{3}}$ \\
\hline MP2 & & & & & & & & \\
6-31G(d,p) & 4.7747 & 8.2 & 0.9851 & 1.4 & 0.8250 & 0.2 & 50.2 & 0.8 \\
6-311G(d,p) & 4.7633 & 19.6 & 0.9843 & 0.6 & 0.8242 & 0.6 & 51.5 & 2.1 \\
6-311+G (d,p) & 4.7563 & 26.6 & 0.9826 & 1.1 & 0.8229 & 1.9 & 59.0 & 9.6 \\
6-311++G(d,p) & 4.7560 & 26.9 & 0.9827 & 0.1 & 0.8229 & 1.9 & 58.8 & $9.4^{\text {a }}$ \\
6-311G(df,pd) & 4.7936 & 10.7 & 0.9923 & 8.6 & 0.8307 & 5.9 & 53.3 & 3.9 \\
6-311+G(df,pd) & 4.7857 & 2.8 & 0.9906 & 6.9 & 0.8293 & 4.5 & 86.9 & 37.5 \\
6-311++G(df,pd) & 4.7854 & 2.5 & 0.9906 & 6.9 & 0.8293 & 4.5 & 72.0 & 22.6 \\
6-311G(2df,2pd) & 4.8076 & 24.7 & 0.9934 & 9.7 & 0.8318 & 7.0 & 42.1 & 7.3 \\
6-311+G(2df,2pd) & 4.8030 & 20.1 & 0.9915 & 7.8 & 0.8304 & 5.6 & 42.9 & 6.5 \\
6-311++G(2df,2pd) & 4.8004 & 17.5 & 0.9920 & 8.3 & 0.8306 & 5.8 & 41.3 & 8.1 \\
aug-cc-pVDZ & 4.6952 & 87.7 & 0.9744 & 9.3 & 0.8153 & 9.5 & 44.8 & 4.6 \\
aug-cc-pVTZ & 4.7896 & 6.7 & 0.9903 & 6.6 & 0.8291 & 4.3 & - & - \\
B3LYP & & & & & & & & \\
6-31G(d,p) & 4.7983 & 15.4 & 0.9775 & 6.2 & 0.8204 & 4.4 & 41.5 & 7.9 \\
6-311G(d,p) & 4.8186 & 35.7 & 0.9783 & 5.4 & 0.8216 & 3.2 & 44.2 & 5.2 \\
6-311+G(d,p) & 4.8158 & 32.9 & 0.9774 & 6.3 & 0.8209 & 3.9 & 45.0 & 4.4 \\
6-311++G(d,p) & 4.8155 & 32.6 & 0.9775 & 6.2 & 0.8209 & 3.9 & 45.1 & 4.3 \\
6-311G(df,pd) & 4.8357 & 52.8 & 0.9815 & 2.2 & 0.8243 & 0.5 & 44.3 & 5.1 \\
6-311+G(df,pd) & 4.8330 & 50.1 & 0.9806 & 3.1 & 0.8236 & 1.2 & 44.9 & 4.5 \\
6-311++G(df,pd) & 4.8327 & 49.8 & 0.9807 & 3.0 & 0.8237 & 1.1 & 45.7 & 3.7 \\
6-311G(2df,2pd) & 4.8441 & 61.2 & 0.9827 & 1.0 & 0.8254 & 0.6 & 41.3 & 8.1 \\
6-311+G(2df,2pd) & 4.8405 & 57.6 & 0.9817 & 2.0 & 0.8245 & 0.3 & 42.1 & 7.3 \\
6-311++G(2df,2pd) & 4.8404 & 57.5 & 0.9817 & 2.0 & 0.8246 & 0.2 & 41.3 & 8.1 \\
aug-cc-pVDZ & 4.7794 & 3.5 & 0.9746 & 9.1 & 0.8179 & 6.9 & 45.9 & 3.5 \\
aug-cc-pVTZ & 4.8388 & 55.9 & 0.9817 & 2.0 & 0.8245 & 0.3 & 45.6 & 3.8 \\
Experimental & $\mathbf{4 . 7 8 2 9}$ & & $\mathbf{0 . 9 8 3 7}$ & & $\mathbf{0 . 8 2 4 8}$ & & 49.4 & \\
\hline
\end{tabular}

